\title{
Head and Neck Carcinoma of Unknown Primary
}

National Cancer Institute

\section{Source}

National Cancer Institute. Head and Neck Carcinoma of Unknown Primary. NCI

Thesaurus. Code C162595.

A carcinoma that has metastasized to the head and neck region from an unknown primary anatomic site. 